\title{
The Effect of Pictorial Models Health Education on Mother Skill in Determining Early Anemia on Primary School Children
}

\author{
Aniharyati ${ }^{1}$, Haris $^{2}$, Ahmad $^{3}$ \\ 1,2,3 Politeknik Kesehatan Mataram
}

\begin{tabular}{|c|c|}
\hline Article Info & Abstract \\
\hline $\begin{array}{l}\text { Article History: } \\
\text { Accepted Sept 15th } 2018 \\
\text { Key words: } \\
\text { Detection of anemia } \\
\text { Pictorial model }\end{array}$ & $\begin{array}{l}\text { Introduction: Early detection of anemia can be performed by mother and } \\
\text { the mother should have knowledge and skills in it. Health education is a } \\
\text { strategy in providing knowledge, comprehension, abilities and skills for } \\
\text { empowerment. This is a quasi-experimental research with pre and post- } \\
\text { test design in the same group. Researchers will assess mothers who have } \\
\text { elementary school children before and after a pictorial model health } \\
\text { education given on how to detect early anemia in primary school children. } \\
\text { This research was conducted in Bontokape Village, Bolo Sub-district, Bima } \\
\text { Regency. The population of this research was } 150 \text { people and } 60 \text { people } \\
\text { were chosen as samples by purposive sampling technique. Data were } \\
\text { analyzed by Wilcoxon test. Results: Unskilled category respondents are } \\
91,7 \% \text { before health education given and decrease to } 0 \% \text { after health } \\
\text { education.Pictorial model health education is significantly influence on } \\
\text { early detection mother skill of anemia in primary school children (p-value } \\
0,00 \text { ). Discussion: Narration and animation in teaching and learning } \\
\text { process is an interesting media and proven effectively to improve learning } \\
\text { result. Pictorial model health education can significantly improve the } \\
\text { mother's skills. }\end{array}$ \\
\hline
\end{tabular}

\section{PENDAHULUAN}

Pemberdayaan keluarga dan masyarakat merupakan sasaran utama dari pendidikan kesehatan. Ibu didalam keluarga sebagai seorang yang memiliki peran utama untuk memelihara kesehatan anak harus memiliki keterampilan guna melaksanakan perannya secara maksimal. Anak adalah harapan bangsa yang akan membenahi dan menata wajah bangsa di masa yang akan datang. Oleh sebab itu, kesehatan anak adalah hal yang sangat mendasar dan prioritas untuk dijaga dan ditingkatkan. Namun, dalam kenyataannya ribuan anak-anak Indonesia masih memiliki masalah dengan kesehatannya. Antara lain adalah anemia.

Anemia adalah istilah yang menunjukan rendahnya hitung sel darah merah dan kadar hemoglobin dan hematokrit dibawah normal (usia 5-11 tahun $\mathrm{Hb}$ Normal 11,5 $\mathrm{gr} / \mathrm{dl})$.

Riskesdas (2013) jumlah kasus anemia pada anak yang berusia 5-14 tahun sebanyak 26,4\% (Kemenkes RI, 2014). Kebiasaan buruk anak-anak di Desa Bontokape yang saat bermain dihalaman rumah dan persawahan tidak memakai alas

Corresponding author:

Aniharyati

rivatbima@gmail.com

Media Keperawatan Indonesia, Vol 1 No 3, October 2018

e-ISSN: 2615-1669

DOI:10.26714/mki.1.3.2018.1-6 
kaki sering menjadi penyebab terjadinya anemia akibat kecacingan. Anak yang menderita anemia akibat kecacingan dapat kehilangan darah sebanyak 2-100 cc dalam sehari (Masrizal 2007).

Dampak lain dari anemia pada anak dapat menyebabkan terhambatnya pertumbuh an dan perkembangan, kekebalan tubuh menurun sehingga anak mudah diserang oleh berbagai macam penyakit. Oleh karena itu, deteksi dini anemia pada anak menjadi sesuatu yang sangat penting dilakukan. Deteksi dini anemia pada anak dapat dilakukan oleh ibu dirumah sebelum membawa anaknya ketempat pelayanan kesehatan. Untuk melakukan deteksi anemia pada anaknya ibu harus memiliki pengetahuan dan keterampilan akan hal itu.

Pendidikan kesehatan merupakan salah satu strategi dalam memberikan pengetahuan, pemahaman, kemampuan dan keterampilan dengan salah satu tujuan adalah pemberdayaan. Peran keluarga sangat diperlukan dalam pengelolaan pasien (Yanto \& Setyawati, 2017). Dengan pengetahuan dan keterampilan yang dimiliki, Ibu menjadi dapat mengambil suatu tindakan untuk menolong dirinya sendiri dan atau keluarganya sebelum mencari tempat pelayanan kesehatan. Pemberdayaan ibu sangat penting untuk dilakukan agar ibu sebagai pengasuh anak dalam keluarga memiliki kemauan, kemampuan dan keterampilan untuk mendeteksi, memelihara dan menjaga kesehatan anaknya.

Menurut Undang-undang Kesehatan No. 23 Tahun 1992 dan WHO, tujuan pendidikan kesehatan adalah meningkatkan kemampuan masyarakat untuk memelihara dan meningkatkan derajat kesehatan; baik secara fisik, mental dan sosialnya, sehingga produktif secara ekonomi maupun social, pendidikan kesehatan disemua program kesehatan; baik pemberantasan penyakit menular, sanitasi lingkungan, gizi masyarakat, pelayanan kesehatan, maupun program kesehatan lainnya (Mubarak, 2009).

\section{METODE}

Penelitian ini merupakan penelitian quasi eksperimen dengan desain pre dan post test pada kelompok yang sama. Peneliti menilai keterampilan ibu yang memiliki anak SD yaitu sebelum dan sesudah diberikan pendidikan kesehatan model bergambar tentang cara mendeteksi dini anemia pada anak Sekolah Dasar. Penilaian dilakukan dengan tehnik observasi dengan mengunakan lembar ceklis. Penelitian dilaksanakan di Desa Bontokape Kecamatan Bolo Kabupaten Bima.

Populasi dalam penelitian ini adalah sebanyak150 orang dan sampel sejumlah 60 orang dengan teknik pengambilan menggunakan Purposive sampling. Untuk mengalisa data digunakan uji Wilcoxon. Dengan batas kemaknaan alpha sebesar 0,05 .

\section{HASIL}

Responden pada penelitian ini adalah Ibu yang memili anak usia sekolah dasar di Desa Bontokape yang berjumlah 60 orang .

Tabel 1.Distribusi keterampilan ibu dalam mendeteksi dini anemia sebelum diberikan pendidikan kesehatan model bergambar.

\begin{tabular}{llr} 
Keterampilan & f & (\%) \\
\hline Tidak Terampil & 55 & 91,7 \\
Cukup Terampil & 4 & 6,7 \\
Terampil & 1 & 1.6 \\
\hline Total & 60 & 100 \\
\hline
\end{tabular}

Hasil penelitian menunjukan bahwa mayoritas ibu memiliki keterampilan dalam kategori tidak Terampil sebanyak 55 responden $(91,7 \%)$ 
Tabel 2. Distribusi keterampilan ibu dalam mendeteksi dini anemia setelah diberikan pendidikan kesehatan model bergambar.

\begin{tabular}{lcl}
\hline Keterampilan & f & (\%) \\
\hline Tidak Terampil & 0 & 0 \\
Cukup Terampil & 5 & 8.3 \\
Terampil & 55 & 91.7 \\
\hline Total & 60 & 100 \\
\hline
\end{tabular}

Berdasarkan tabel 2. dapat diketahui bahwa mayoritas responden berada dalam kategori terampilan yaitu sebanyak 55 responden $(91.7 \%)$.

Tabel 3. Hasil analisa pengaruh pendidikan kesehatan model bergambar terhadap Keterampilan ibu dalam mendeteksi dini anemia pada anak Sekolah Dasar

$\begin{array}{llll}\text { Variabel } & \mathrm{Z} & p & \mathrm{~N} \\ & \text { value } & \end{array}$

\begin{tabular}{llll} 
Skor Pre Pendkes & -7.242 & & \\
Skor post pendkes & -7.242 & 0,000 & 60 \\
\hline
\end{tabular}

Berdasarkan tabel 3. terlihat bahwa nilai $\mathrm{p}$ value adalah 0.000. Dapat disimpulkan

bahwa ada pengaruh pendidikan kesehatan model bergambar terhadap keterampilan ibu dalam mendeteteksi dini Anemia pada anak sekolah dasar dengan nilai signifikansi 0,000 .

\section{PEMBAHASAN}

\section{Keterampilan Ibu Sebelum Diberikan Pendidikan Kesehatan Model Bergambar}

Berdasarkan penelitian didapatkan hasil bahwa sebagian besar responden mempunyai keterampilan dalam kategori tidak terampil sebanyak 58 orang (43.4\%). Keterampilan responden dipengaruhi oleh beberapa faktor antara lain adalah pengetahuan yang masih kurang tentang Deteksi Dini Anemia serta belum pernah ada pendidikan kesehatan semacam ini sebelumnya. Responden hanya mengetahui tanda dan gejala anemia adalah Lemah, letih dan lesu.
Berdasar Hasil penelitian juga didapatkan bahwa responden yang memiliki keterampilan cukup sebanyak 4 responden $(6,7 \%)$ dan yang terampil 1 orang $(1,6 \%)$. Responden tersebut memiliki tingkat pendidikan perguruan tinggi dan merupakan kader posyandu, dimana telah terpapar oleh informasi-informasi kesehatan oleh tenaga kesehatan saat melakukan kegiatan posyandu. Pendidikan berbanding lurus dengan proses belajar dan kemamapuan menerima informasi. seseorang yang informasi tentang kesehatannya banyak maka orang tersebut akan bersikap, berperilaku dan patuh dalam melaksanakan program kesehatan (Pery and Potter, 2009). Keterampilan dapat ditunjukan melalui perilaku yang merupakan hasil dari pemahaman dan pengetahuan seseorang tentang sesuatu. (Sudijono cit Ludfimayanasari 2004). Hasil penelitian Aruna Ramasany (2013) mengatakan bahwa terdapat hubungan antara tingkat pendidikan dengan pengetahuan tentang Antenatal Care dikalangan ibu usia subur di PKM Padang Pulan.

\section{Keterampilan Ibu Sesudah Diberi Pendidikan Kesehatan Model Bergambar}

Berdasarkan hasil penelitian mayoritas responden sebelum diberi pendidikan kesehatan Model bergambar dalam kategori tidak terampil 91,7\% sedangkan setelah diberi pendidikan kesehatan Model bergambar terjadi perubahan keterampilan pada responden, dimana responden yang berada dalam kategori terampil sebesar $91,7 \%$. Data tersebut menujukan bahwa pendidikan kesehatan model bergambar tentang pemeriksaan Deteksi Dini Anemia pada anak sekolah Dasar telah mampu meningkatkan keterampilan ibu dalam mendeteksi Dini Anemia. Diadakanya pendidikan kesehatan model bergambar tentang Deteksi Dini Anemia pada anak sekolah dasar diharapkan dapat meningkatkan pengetahuan, dan keterampilan ibu. Pengetahuan dikatakan meningkat bila terjadi perubahan dari tidak 
tahu menjadi tahu dan yang sudah tahu menjadi lebih tahu. Keterampilan dapat disimpulkan meningkat bila menunjukan perubahan dari tidak bisa menjadi bisa melakukan sesuatu hal positif dan bermanfaat.

Terdapat 5 responden $(8,3 \%)$ yang memiliki keterampilan cukup. Hal ini terjadi pada wanita yang berpendidikan sekolah dasar dan menengah. Menurut Notoadmodjo (2010), pendidikan berpengaruh pada kemampuan seseorang dalam menyerap informasi. Hal ini berarti bahwa semakin tinggi pendidikan, maka akan semakin mudah dalam menerima dan memahami suatu informasi. Pada ibu yang berpendidikan dasar, kemungkinan untuk menerima informasi pendidikan kesehatan tentang Deteksi Dini Anemia lebih sukar daripada ibu yang berpendidikan menengah Atas dan tinggi.

Penelitian ini juga sejalan dengan studi lain, bahwa pendidikan kesehatan adalah proses menuju perubahan, dengan tujuan agar individu dan kelompok maupun masyarakat, mengarah ke hal-hal yang baik dan positif secara sadar dan terencana Perubahan-perubahan yang dimaksud adalah antara lain perubahan pengetahuan, perubahan sikap dan perubahan keterampilan melalui proses pendidikan kesehatan. Penelitian ini didukung oleh penelitian Simanulang (2012), yang menunjukan bahwa ibu yang diberi pendidikan kesehatan tentang sadari dapat mempraktekan teknik sadari dalam kehidupan sehari-hari.

\section{Pengaruh Pendidikan Kesehatan Model Bergambar Terhadap Keterampilan Ibu Dalam Mendeteksi Dini Anemia Pada Anak Sekolah Dasar}

Hasil analisis Wilcoxon menujukan bahwa nilai signifikansi 0,000 yang berarti terdapat pengaruh yang signifikan antara pendidikan kesehatan model bergambar tentang Deteksi Dini Anemia dengan keterampilan dalam medeteksi dini tanda dan gejala anemia pada anak Sekolah Dasar. Keterampilan merupakan kemampuan seseorang dalam bertindak setelah terlebih dahulu memperoleh pengetahuan dan sikap. Keterampilan Deteksi Dini Anemia pada anak sekolah dasar setelah dilakukan setelah diberi pendidikan kesehatan model bergambar meningkat menjadi 91,7 \% yang berada dalam kategori terampil dibandingkan dengan sebelum dilakukan pendidikan kesehatan yaitu sebanyak 91,7 $\%$ yang berada justru dalam kategori tidak terampil. Hal ini didukung oleh penelitian yang dilakukan oleh Musfiroh (2014) yang menyatakan bahwa tindakan pemberian pendidikan kesehatan dapat memperjelas informasi sehingga akhirnya dapat meningkatkan sikap posifif seseorang.

Penyampaian materi dalam memberikan pendididkan kesehatan sebaiknya menggunakan alat peraga agar menarik perhatian sasaran, materi yang diberikan adalah kebutuhan dasar yang menjadi masalah kesehatan yang dihadapi sasaran.

Menurut Notoatmodjo (2007), Penyuluhan dan atau menyebarluaskan informasi yang dilakukan melalui media visual seperti lembar palik, booklet, poster, dalam penelitian dan pendidikan kesehatan telah banyak dilakukan, hasilnya menunjukkan adanya peningkatan pengetahuan. Hasil penelitian oleh Yusyaf (2011) menunjukan ada perbedaan kearah peningkatan pengetahuan sesudah diberi pendidikan kesehatan menggunakan media lembar balik. pada kelompok eksperimen. Media visual (gambar) memberikan rangsangan melalui mata. Media visual (gambar) yang menarik dapat menfokuskan perhatian individu dan pesan yang disampaikan akan lebih mudah untuk dipahami. Organ yang paling banyak menyalurkan pengetahuan adalah mata yaitu lebih kurang 75-87 \% pengetahuan manusia diperoleh atau disalurkan melalui mata, dan 13-25\% lainnya tersalurkan melalui telinga atau indra lain. Oleh karena itu, disarankan dalam untuk mempergunakan alat-alat visual dan audiovisual dalam aplikasi 
pembuatan media karena media tersebut dapat membantu mempermudah dalam menyampaikan dan menerima informasi oleh masyarakat (Maulana, 2009).

Kelebihan dari pendidikan kesehatan melalui model bergambar adalah dapat dilihat berulang-ulang dan dapat dibawa pulang oleh responden. Penggunaan media model bergambar menjadikan pendidikan kesehatan lebih menarik dan tidak membosankan. Hal tersebut dapat membuat responden yang diberikan pendidikan kesehatan melalui model bergambar tidak mudah bosan dan tertarik untuk memperhatikan informasi yang diberikan. Pada model bergambar, berisi tambahan informasi berupa keterangan pada tiap gambar untuk menambah kejelasan informasi tentang tanda dan gejala anemia pada anak sekolah dasar. Responden saat diberikan pendidikan kesehatan lebih serius memperhatikan penjelasan yang diberikan. Hal ini didukung oleh penelitian Saguni (2006), membuktikan bahwa penggunaan media narasi dan animas cukup efektif untuk meningkatkan hasil belajar. Oleh karena itu, kejelasan informasi yang diberikan melalui model bergambar dapat meningkatkan keterampilan ibu dalam mendeteksi dini anemia pada anak sekolah dasar.Kenyataan membuktikan bahwa pendidikan kesehatan model bergambar tidak hanya meningkatkan keterampilan ibu, tetapi memberikan solusi terbaik bagi ibu-ibu yang memiliki kendala dengan waktu dan biaya untuk pergi ke tempat pelayanan kesehatan guna memeriksa kondisi anaknya. Riskesdas (2013) menunjukan masih cukup tingginya kasus anemia yang diderita oleh anak usia 5-14 tahun yaitu sebanyak 26,4\% (Kemenkes RI, 2014).

Secara pasti anemia dapat didiagnosa melalui pemeriksaan laboratorium di tempat-tempat pelayanan kesehatan seperti laboratorium Puskesmas, RS dan Klinik, akan tetapi dengan adanya keterampilan ibu dalam mendeteksi dini tanda dan gejala anemia pada anak, ibu dapat melakukannya sendiri di rumah tanpa memerlukan biaya dan waktu yang lama.

Hasil penelitian ini juga dapat memberikan kontribusi positif terhadap program pemerintah dalam rangka pemberdayaan masyarakat, dimana masyarakat (ibu) mampu mengenal dan mengidentifikasi permasalahan-permasalahan kesehatan, dalam hal ini masalah anemia yang dialami oleh anaknya.

\section{SIMPULAN}

Bahwa keterampilan responden sebelum diberi pendididikan kesehatan berada pada ketegori tidak terampil. Proses belajar mengajar dengan menggunakan narasi dan animasi merupakan media yang menarik dan terbukti cukup efektif untuk meningkatkan hasil belajar. Pendidikan kesehatan dengan menggunakan model bergambar dapat meningkatkan keterampilan ibu secara signifikan.

\section{REFERENSI}

Almatsier, S.(2010).Prinsip Dasar Ilmu Gizi.Jakarta : Gramedia Pustaka Utama. Andi Offset.

Arief, M., Kuspuji, T.\& Rakhmi, S.(2007).Kapita selektra kedokteran.Edisi ke-3.Jakarta:Media Aesculapius.

Dimyati, V. (2011). Anak Usia Sekolah Berisiko Anemia.hal-9.Jurnal Nasional.

Gibney, J., Margaretts, M., Kearney, J. \& Arab, L. (2008).Gizi kesehatan masyarakat.Jakarta:EGC.

Jurnal Kesmas II (1) (2016) 16-24 Pengaruh media film terhadap sikap ibu dalam deteksi dini $\mathrm{Ca}$ ceviks.

Kapti, R.E (2010) Efektifitas audiovisual sebagai media penyuluhan kesehatan terhadap peningkatan pengetahuan dan sikap ibu dalam tatalaksana balita dengan diare di dua Rumah sakit kota Malang, diperoleh tanggal 25 oktober 2017, http: lontar.ui.ac.id/file = digital/137097-T $\% 20$ Rinik\%20Eko\%Kapti.pdf.

Kemenkes RI, 2014. Riset Kesehatan Dasar 2013. 
Notoatmodjo S. ; 2012, Promosi Kesehatan dan perilaku kesehatan. Jakarta: PT Rineka Cipta.

Nursalam, S. \& Rekawati,U,S.(2005).Asuhan Keperawatan Bayi dan Anak (untuk perawat dan Bidan).Edisi Pertama-Jakarta:Salemba Medika.72

Staf Pengajar Ilmu Kesehatan Anak. Buku Kuliah 2 Ilmu Kesehatan Anak 4th ed. Jakarta: Bagian
Ilmu Kesehatan Anak Fakultas Kedokteran Universitas Indonesia; 2007.

Yanto, A., \& Setyawati, D. (2017a). Dukungan Keluarga Pada Pasien Diabetes Mellitus Tipe 2 Di Kota Semarang. Paper presented at the PROSIDING SEMINAR NASIONAL \& INTERNASIONAL. 